\title{
WHY HANDS ON HISTORY MATTERS
}

\author{
John Ellis
}

The hands on approach to history responds to the presence of complex technologies in all aspects of human existence since the industrial revolution, and in particular to the recent growth of 'black box' electronic devices. The 'gamble' of the hands on approach is that the physical experience of machinery brings insights that cannot be gained in any other way. It is a commonplace that most people, faced with an unfamiliar piece of technology, do not read the instruction manual. Instead, they try it out. The interaction of body, mind, and machine that results from these encounters enables learning and develops skills. So it is with the experience of an unfamiliar piece of historical technology. Written descriptions are not enough to develop a real understanding of the machine and its functioning. Physical experience is needed to inform the understanding, and to eliminate misapprehensions and misunderstandings. Once someone has handled a film projector, they can more easily understand how it worked, what its particular affordances were, and what 'aura' it could create in the cinematic experience. Similarly, just to pick up a film camera gives a vivid experience of its particular 'heft', its weight, balance, and manoeuvrability, and that physical experience gives insight into how it could (and could not) be used in practice.

To go this far is a valuable educational experience, and should be a key part of any researcher's training. Beyond it lie a further series of questions. It is clear to begin with that the experience of handling a single piece of technology as a novice will be very different from that of either an experienced user or a trained professional user. This leads some to propose a 'media archaeology' that seeks to explore the many potential affordances of the many machines that come down to us from history, rather than the affordances that were realized in the context of their historically situated use (Ernst 2012; Parikka 2012, etc.). This certainly works with mechanical devices of all kinds (Huhtamo and Parikka 2011), and it is important in encouraging researchers to enter into a new mindset: that of the skilled user of a 
technology. However, its application to the 'black box' technologies that are now proliferating is less obvious, as these technologies are effectively scattered across the physical and the virtual, between the tool at hand and the software and data services that it requires to give it life.

Moreover, the affordances of technologies are always realized within historically situated institutional implementations, and technologies are often designed with these in mind. Institutional considerations will also bear down even on those seeking alternative or counterfactual uses, just as much as they do on mainstream and everyday uses. Experimental media archaeology will always take place within institutions of experimentation or 'play': universities, museums, hackathons, and so on. Histories of the institutions of television broadcasting exist for many national contexts. Equally, we also have several traditions of advanced analysis of the products of the process, the films, and programmes. But there are hardly any accounts of the space that lies between the decisions by executives to invest in and deploy particular suites of technologies, and the emergence of those films and programmes on the other. This is the underexplored realm of enactment or operationalization. Often labelled misleadingly as 'media practice', this is the complex arena where creative decisions are made in full awareness of the institutional requirements for particular kinds of aesthetic products. Media professionals know what is required of them and they deliver it; they equally know that one of the requirements of them is a degree of originality or innovation, and they will often look to the underexplored affordances of the available technology to help deliver that degree of innovation. 'Media practice' is therefore a dynamic realm which is best understood by addressing the interplay of people and machines, and machines with other machines.

It is also clear from media practice that machines, even analogue machines, are not typically used alone: they occur in larger ensembles, as part of complex processes that have various stages or involve the use of several machines at once. To film using celluloid involves a camera, lights, and sound recorders; the product of that initial process then passes through further stages of film development, editing, dubbing, and printing, and, finally, projection. Each stage involves particular skills and individuals with a high level of skill in one stage may well be unable to carry out a basic operation in another. Hands on history has to come to terms with these key aspects of the imbrication of humans with technologies. It has to enable the novice users to translate their experiences and insights into a full understanding of the human/technological ensemble which, at a particular moment in history, was capable of producing extraordinary objects and experiences. Hands on history, in other words, has to come to terms with the processes of that skilled individuals went through, just as much as it has to enable an exploratory and experiential approach to learning.

This implies a process of documentation of the work of skilled individuals. Alongside the experiential knowledge generated by handling and experimenting with old machines, the hands on approach has to develop of knowledge bank of information about the skilled use of those machines in the circumstances of their historically situated implementation. These certainly involve industrial and 
institutional contexts of which we have authoritative accounts as noted earlier. However, when it comes to accounts of the operation of the machines involved, we run up against a set of problems. The users of the technologies, as a rule, do not have the descriptive or analytic discourses to describe systematically what they used to do. So much is tied up in their muscle memory, in the things that they had to learn to do automatically. The approach adopted by the ERC funded ADAPT research project (2013-8) was to go beyond interviews and stage encounters between equipment and their skilled users. ${ }^{1}$ The simplest of these encounters involved individuals explaining and demonstrating particular pieces of equipment. Even these encounters yielded far more than a conventional interview because the physical presence equipment triggered fresh memories and the opportunity to handle it once again enabled a voyage of discovery. The ADAPT project was also far more ambitious in enabling encounters between teams of former professionals and the arrays of equipment they used, together, to produce television. The chapters by Amanda Murphy, Nick Hall, and Vanessa Jackson in this collection all explore aspects of this work.

In a way, this method simply develops what most individuals do when they are faced with a piece of equipment. They do not reach for the instructions handbook, even in the increasingly rare cases where such a thing is provided. Instead, they resort to the audio-visual 'how to' material that can easily be found on YouTube and elsewhere. Audio-visual accounts are clearly the preferable complement to the physical experience of a piece of machinery as they, too, demonstrate the involvement of hand and eye, mind and body. The ADAPT project applied this insight successfully to documenting the activities of the skilled professionals who made broadcast television programmes in the analogue era, as is described by Murphy and Hall elsewhere in this collection. This process of documentation requires considerable modifications to traditional research methods. It requires that curators and researchers enter unfamiliar kinds of engagements with objects and with people. It also requires a fresh approach to the presentation of documentation (for example, as 'how they used to' videos as well as written accounts).

The hands on method renders visible and perceptible aspects of human experience that have been neglected by exclusively written, word-based analyses. The use of audio-visual documentation of hands on practices makes visible much that has escaped analysis in the past. Viewing filmed footage opens up the world to a fresh process of seeing. The viewer is enabled to see actions, attitudes and exchanges that would have been overlooked by even alert observers during the actual filming. Multiple camera points of view can capture interactions of people with people, people with machines, and machines with machines that are simply too complex or too fleeting to be apprehended in the flow of events. Recent media theory (Nichols 1991; Renov 1993; Bruzzi 2006; Ellis 2012, etc.), has emphasized that documentary filming is a specific form of intervention into the world, enabling a reconstruction of vision that is both mobile and analytic. The camera and the sound recorder can be seen as new extensions of the human, enabling new explorations of the world by the very act of preserving moments 
for later inspection. Further, they enable forms of selection and rearrangement of motion in time and space that can open them up to further analysis. This is particularly the case when using a set-up of multiple cameras and sound recorders, as is now possible. From this perspective, it might seem odd that the filming of activities (rather than interviews) is not a more standard approach to social research. However, the technological arrays that would be both suitable and affordable are only just becoming available, and, as Amanda Murphy explores in this collection, the current working practices of television also require adaptation before they can be deployed in a research setting.

The gains from a hands on approach will be great. Researchers will at last be able to perceive that which is not easily articulated in words alone. The 'hands on' method combines audio-visual recording and with the direct sensory experiences of researchers. Researchers deploy a combination of audio-visual recording of skilled users with the immersion of the researcher into similar or analogous physical interactions with those machines. They would both experience for themselves and observe the experiences of others. This would enable researchers to perceive the physicality of human/machine interactions; to grasp the processes that are not verbalized by the human participants in those activities; and, importantly, to observe the activities of teams of humans working with arrays of machinery.

The hands on approach provides a solution to the problem of ethnography so eloquently posed by Geertz (1973) in describing his method of 'thick description':

Doing ethnography is like trying to read (in the sense of 'construct a reading of') a manuscript - foreign, faded, full of ellipses, incoherencies, suspicious emendations, and tendentious commentaries, but written not in conventionalized graphs of sound but in transient examples of shaped behaviour.

(Geertz 1973, 10)

Geertz further emphasizes that any kind of ethnographic description

is interpretative; what it is interpretive of is the flow of social discourse; and the interpreting involved consists of trying to rescue the 'said' of such discourse from its perishing occasions and fix it in perusable terms.

(Geertz 1973, 20)

Audio-visual recording using multiple cameras enables the fixing of Geertz's 'perishing occasions'; and then the researcher's own hands on experience guides the interpretive process. This hands on approach provides access to the experiences of the skilled users of technologies, whether they are professionals going about a defined task, or citizens interacting with the many devices that populate the everyday world. So this method can tell us about how 'being in the world' has been and is now constituted. It can reveal the nature of what has been termed 'the new hybrid', or 'hybrid agents': how human and machine work together as a single 
entity. As Daniel Miller (2010, cover) remarked "things make us just as much as we make things", an insight that only increases in relevance as microelectronics are deployed across everyday life.

The 'gamble' of the hands on approach is therefore an intellectual approach that has important consequences for our attitudes to knowledge and learning. The hands on approach to technologies explored here would have several stages, each of which has its own value and importance for the researcher. In summary, they are:

1. To obtain and explore a machine for its affordances. The researcher(s) see, feel and understand how it works and what it might be capable of doing when free of the institutional constraints in which it was, historically, deployed.

2. To experiment with combinations of machines to discover how they work together and what they might be capable of achieving, understanding the way that machines have a transformative and combinatory potential.

3. To discover and document the communities that have developed advanced skills in combination with the machines within defined historical contexts.

4. To document the ensembles of machinery, the technical arrays and the working practices into which they are or were inserted.

5. To experiment with using, or getting professionals to use, those technical arrays in the way that they were once used. This will discover 'from the inside' what mutual adaptations were involved of people to machines, machines to people, and people to people.

6. To understand both the affordances of the machines and the affordances of the institutions or work-places into which they are or were inserted. These two classes of affordances are mutually determining: the individuals operating within institutions explore the affordances of the technologies; the institutions mould these affordances to their aims; and the designers of technologies take account of their institutional deployment.

\section{The importance of the hands on approach}

The approach outlined above has yielded substantial insights when deployed in the ADAPT project. Two examples will demonstrate their nature. Early in the project's history, an initial experimental 'simulation' (as the project designated professional/equipment encounters, see Hall) was mounted using an extant $16 \mathrm{~mm}$ film cutting room that survived at the London Film School. Once commonplace when most television production outside studios or major live events used film, these technological arrays have almost disappeared. In addition to the iconic editing table (Steenbeck being a key manufacturer), these rooms included large amounts of ancillary equipment: bins for the off-cuts of footage, cans for storage of film reels, rewind benches and cores to wind film round, chinagraph pencils to mark them with, and, crucially, a Pic-Sync for coordinating the strips of magnetic $16 \mathrm{~mm}$ 
footage to which the sound tape recordings had been transferred to the $16 \mathrm{~mm}$ film footage. We were fortunate find this survival that still contained all these items in working order. The simulation also involved two generations of editors, Oliver White and Dawn Trotman.

Dawn Trotman had begun as Oliver's assistant and had quickly graduated to being an editor in her own right. She began cutting $16 \mathrm{~mm}$ film for a variety of purposes (news, documentary, inserts into studio drama) at the BBC's regional centre in Birmingham (see Vanessa Jackson's chapter in this collection) and ended up as the senior coordinating editor for the BBC's flagship and highly popular early Sunday evening magazine series Countryfile, a digital editing operation that she carried out using professional equipment largely based in her home.

When Trotman was reunited with the Pic-Sync, a machine that she used daily when starting out in film editing, she reacted in a highly specific way. When Trotman met the Pic-Sync again, it had already been loaded with two film strips. As a professional, she knew not to intervene in an existing set-up, but she immediately wanted to discover whether she still could remember how to use it. So, giving a verbal account as she goes, her hands hover over the intricate machine as she mimes how her hands used to move. Her physical muscle memory enables her to recall and give an account of the stages of work that she used to go through. In a conventional interview, she would not have easily (if at all) been able to give a detailed and comprehensible account of the activity of syncing up, because that would require her to describe both machine and her operation of it in a way that separated the one from another. For her, the machine and her actions in operating it were an indivisible unit.

Again, a later simulation reunited a group of $\mathrm{BBC}$ vision engineers with their 1970s workspace in the outside broadcast truck or 'scanner', North 3. On sitting down in their workspace for the first time for over 30 years, they all instinctively adopt the same physical position in relation to the controls that they operate. They sit well back in their seats, with arms outstretched in front of them, fingers splayed and hovering over the controls (see Figure 1.5). They developed this distinctive stance as a means of hand/eye coordination. They were required to scan a number of monitors in front of them for potential faults in the adjustment of the three or four cameras being used. They had to react as quickly as possible by making compensatory adjustments. This stance is a learned reaction to this set of circumstances, and provides the best way of carrying out their work. Here, the technology has changed its operators, and their bodies alone contain the information that guides them to take this stance. Even if they did, by some exceptional effort, produce an adequate account of how the equipment worked and how they worked with it, we would still run up against the 'instruction manual' problem described earlier. They would simply not be aware that they had learned this way of arranging their bodies. So the researcher, as a novice user, would find it difficult or impossible to relate their own physical orientations towards the technology in the way that professionals used to. No written account of the work of its previous operators would have remarked on this. 

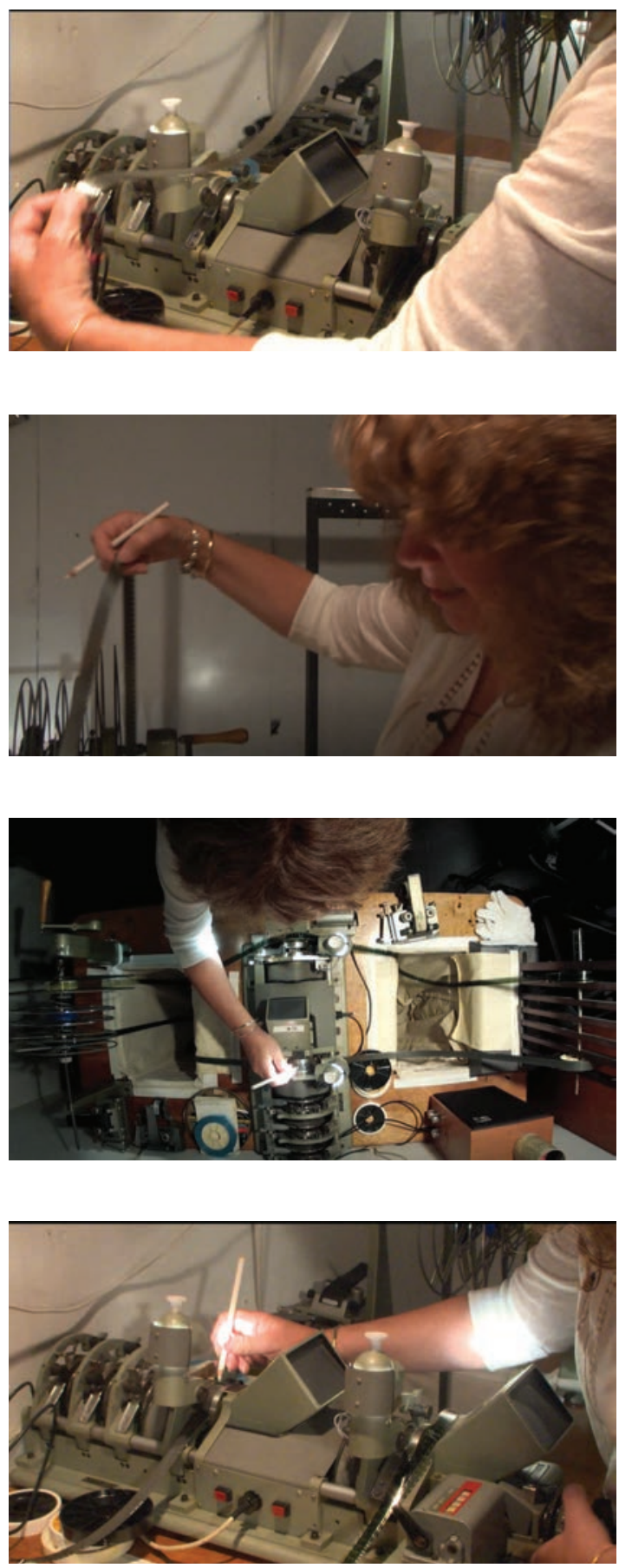

FIGURES 1.1-1.4 Television film and video editor Dawn Trotman demonstrating the use of an Acmade Pic-Sync during an ADAPT project reenactment exercise. 


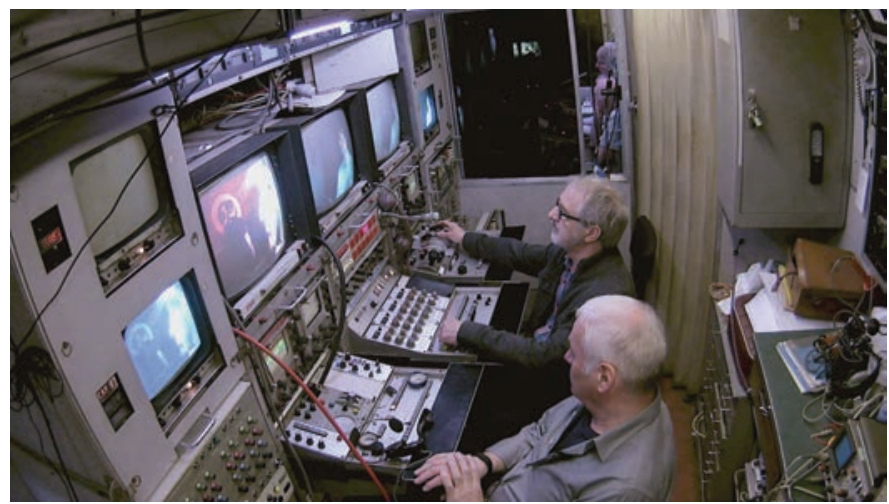

FIGURE 1.5 Vision engineers Bill Baldock and John Coupe at work inside North 3, an outside broadcast vehicle formerly owned by the BBC.

These examples demonstrate that the hands on approach reveals important information about the relationship between humans and the technologies that they use habitually. They show the inadequacy of much current everyday thinking about our relationships with the machines that we use and that use us. These habits of thought are framed within a problematic of mind-intentionality-agency that relegates physical objects and technologies to the status of things which do our bidding and simply aid us to achieve our intentions. When we conceptualize 'tools', we tend to regard them as objects which enable us to carry out our predetermined plans: we think, they do. We regard tools are the extension of capacities within the brain and the body. We believe that tools enable us to realize our previously planned intentions; that Homo sapiens has agency, and things do not. In such a perspective, skilled practice tends to be regarded as habit, an automatic engagement with the material world, which explains the often self-deprecating or even subservient attitudes of many 'technicians'.

Against this attitude can be set the idea of the 'hybrid agent' where the body and the tool become an extended unit, 'the tooled body', a new kind of perceptual and cognitive unit. Latour uses the telling example of the gunman, which, once expressed in English, provides a literal rendering of the fusion of human and tool. As Latour puts it:

neither the isolated gun nor the isolated individual can bear the responsibility for the act of killing. The responsibility lies, on the one hand, in the way those two agents come together to construct a new hybrid agent- the gunman-and, on the other, in the socio-technical network that supports and makes possible such a meeting.

(Latour 1999, 190)

This careful formulation emphasizes that the hybrid agent is socially constructed. It requires a specific culture to enable the encounter to take place by making the 
technology of the gun available, and by the 'support' that it provides in supplying an ethical framework justifying the deployment of the gun not simply for 'deterrence' but for practical action. Latour concludes that for this hybrid actor, "action involves a coalescence of human and non-human elements, and thus the responsibility for action must be shared among those elements" (Latour 1999, 182). The implications of this position are clear: gun culture as well as the gunman are responsible for the specific action of killing. But so deeply ingrained is the attitude that tools simply do our bidding that the person is punished and the culture or subculture escapes.

Another example can be found in the idea of the 'cameraman' or, better, 'filmer': the hybrid agent constructed in the organized encounter between a camera and its experienced operator. The veteran filmer Brian Tufano provided a clear example of this when enabled by a hands on history experiment conducted as part of the ADAPT project. Tufano's long career as a cameraman began when he was promoted to the role at the BBC in 1963, almost coinciding with the introduction of a new generation of $16 \mathrm{~mm}$ film cameras that were far lighter than was previous possible. Tufano left the BBC in 1978 to shoot feature films, including Trainspotting (1996), Billy Elliot (2000) and Kidulthood (2006). At the BBC, he was a crucial member of the team making the BBC2 documentary series Man Alive, which pioneered a form of documentary that emphasized personal stories and real-life situations.

Tufano demonstrated the series of cameras he had worked with as an assistant, showing the problems that they posed for hand-held work. "You could hardly be subtle with something like this [Arriflex ST with external blimp], or even this [selfblimped Arriflex ST] which was considered great in its day." Tufano was part of a wide movement amongst filmers in the mid-twentieth century, a movement that sought to produce a new kind of hybrid agent: a filmer who could move within situations rather than observe them from a series of more or less fixed positions. They wanted to get the camera off the tripod, and be "mobile" as he puts it, moving into the action as it developed, in concert with the sound recordist. Although enabled to move around within events, they continued to conceive of their role as one of observation, rather than intervention. Hence Tufano's use of the words 'subtle' and 'unobtrusive'.

Tufano comments on the lightweight Éclair camera after he has held it and repeated some familiar actions. He tells how he "suddenly felt a sense of freedom" and emphasizes that the Éclair was balanced and felt comfortable when handheld. He then pauses and reflects, producing rather haltingly the statement that "I thought of my body as a kind of Steadicam": the device, invented far later, which compensates for the movements of the body which, when transmitted to the camera, can produce a distractingly 'wobbly' image. It was a matter of "being as flexible as possible" and "going into the gym and building up your upper body strength and your legs". This is a clear description of a cameraman adapting his body to the equipment he was using. He goes further to outline some new perceptual methods that he had to learn as well: "if you go into a dangerous situation, you need to be as alert as possible, so its learning to use left eye as well as your right eye". When the right eye is looking down the camera viewfinder, the natural response is to 
close the left eye. However, the vigilant filmer needs to keep the left eye open and to monitor what is going on around. As well as these physical and perceptual modifications to himself, Tufano also made a series of modifications to the camera, installing an exposure meter and using a particular set of controls for the zoom lens that best suited his mode of operation. Finally, he adopted a newly developed battery belt to replace the battery box designed to be slung across the shoulder.

Tufano gives a clear account and demonstration of the process of mutual adaptation necessary to produce a new fused entity: the hybrid agent of the Éclair filmer. The machine offers new affordances whose realization in practice required physical and perceptual changes in the cameraperson, as well as adaptations of the machine to the operator. Tufano's vivid analysis of this process offers the same radical perspective as that of Bernard Stiegler who regards the human as a prosthetic being: "The prosthesis is not a mere extension of the human body; it is the constitution of this body qua "human" Stiegler $(1998,152)$. The camera here is not a tool of a human; it is a prosthesis that allows the extension and mutation of human perception and action into a new field. The camera takes the human capacity of vision and allies it to the process of recording. As part of a larger ensemble of technologies, it participates in a process that brings that recorded event to others who can observe in tranquillity. The new hybrid agent of camera and filmer extends that capacity for recorded seeing by giving it a mobility within the action being filmed as it develops. It provides the ability to follow and observe human actors, to shift focus and attention within a space, to reframe according to the dictates of the action or the editorial preoccupations of the filmer. This new hybrid actor is capable of a new kind of intervention in events that is qualitatively different from that of the eyewitness, and enables a further new kind of seeing in those who witness events through the recorded and edited images and sounds (see Frosh and Pinchevski 2009). The filmer effectively rethinks time, space and events for a new category of absent and distant viewer. We are still working through the implications of this new hybrid actor for society.

Latour's account of the new hybrid 'gunman' is couched in terms of a story of combining two hitherto separate entities. That is what gives it an explanatory impact. Tufano's account of his process of becoming what I have called 'an Éclair filmer' requires that we go further. It requires a more detailed examination of the encounter between person and technology to ask what we do when we think, and in particular whether we are mistaken in our understanding of the relationship between our minds and our tools.

The archaeologist and anthropologist Lambros Malafouris (2013) has developed fresh approach to this issue from his theorization of the earliest toolmaking activities of humanity. Drawing on ideas from Latour, Appadurai, and others, he proposes a 'material engagement theory', which posits that human think through things.

Human cognitive and emotional states or processes literally comprise elements in their surrounding material environment. . . Our ways of thinking 
are not merely causally dependent upon but constituted by extracranial bodily processes and material artifacts.

(Malafouris 2013, 228)

We do not think and then use things, in other words. Rather, we think through and with the material world. Thinking emerges through the material engagement with things in the world and is formed and developed in those encounters. Malafouris gives the example of a Stone Age person engaged in the activity of hand-knapping: using a suitably shaped flint to create a keen-edged handaxe from another piece of flint.

Instead of seeing in the shaping of the handaxe the execution of a preconceived 'internal' mental plan, we should see an 'act of embodying.' . . . In tool making, most of the thinking happens where the hand meets the stone. There is little deliberate planning, but there is a great deal of approximation, anticipation, and guessing about how the material will behave. . . . Sometimes the material collaborates; sometimes it resists. In time, out of this evolving tension comes precision and thus skillfulness. Knapping, then, should be seen more as an active 'exploration' than as a passive 'externalization' or 'imposition of form'.

This is a dramatic example of thinking with and through the material world, and has many similarities with the accounts of filmers as they engage with the events they are filming, whether they are pre-planned or spontaneous. The remark that "there is a great deal of approximation, anticipation and guessing about how the material will behave" could well be applied to documentary filmmaking and even to many kinds of fiction as well. The "evolving tension" that arises in repeating the action to gain "precision and thus skilfulness" describes the difficult process of acquiring the skills necessary for the task.

Malafouris is dealing with what might appear to be a simple cultural process, one of creating tools from the interaction of two natural objects and one human. This may appear to be a long way from the situations encountered today. However, the knapping of flints is always already inserted into a pattern of activity, and required by defined needs: the knapped flints are used for making weapons, scraping skins, cutting meat, and carving bone. The activity takes place, in other words, within an always-already existing technological context where other tools like fire also exist and call into existence the need for sharp edged implements. Malafouris is describing an encounter with objects (in this case drawn from the natural world) which is essentially no different from our contemporary encounters with the always-already existing world of technological objects that we are able to deploy ... if we can discover how to operate them.

So Malafouris's description of the combined physical/mental process of creating knapped flints can be applied equally to the activity of editing, the remaking of 
the captured sounds and images into a meaningful ensemble. Editing is famously an iterative process of trying out combinations of material to find out what works best as a meaningful whole. In film editing, this is a physical process (director Charles Crichton described in the documentary Distilling Whisky Galore (Grigor 1991) working as assistant to Zoltan Korda who ripped the film with his teeth). Digital editing dispenses with the directly physical encounter with strips of film, but the same iterative process is still at its heart. Colour grading, telecine and sound mixing other processes also involve the same exploratory process of material engagement. The material is in the eye and ear rather than the hand. Technicians vary elements and their combination to discover what 'works' for the particular purpose they have in mind. It is no different from flint-knapping except that the desired result is not a sharp edge that can be sits well in the hand, but an audiovisual text that is both meaningful and pleasurable for its anticipated users.

Malafouris makes a distinction between the mind and the brain. The mind, he claims, exists in the interaction of human and tools. This distinction reveals the imbrication of the human and the physical in processes which lie beyond the brain. It also requires that we regard the concept of 'agency' in a different way. The power to act is usually seen as an exclusively human capability. However Malafouris argues that "Agency and intentionality may not be innate properties of things, but they are not innate properties of humans either; they are emergent properties of material engagement" (2013, 148-149). Agency emerges from the interaction of humans and the material world. Agency and intentionality emerge from the encounter between the human and the material world into which she or he is born, a world that in our time increasingly involves everyday and intimate technologies.

Our starting point cannot be that of conscious agency as an innate property of humans. The feeling of agency should be seen as an emergent property of action rather than as an a priori possession of the embodied biological organism. From this perspective, achieving agency is a process inseparable from becoming human.

This much emerges from actor network theory. Malafouris then ventures into research in neuro-psychology, citing the famous (or infamous) research into the brain development of London taxi drivers who are required to have a comprehensive knowledge ("The Knowledge" as they call it) of the location and interrelation of London's streets. Research has shown that the acquisition of The Knowledge produces physical changes in the brains of taxi drivers, with an increase in the size of the hypothalamus. Research into musicians has revealed similar enhancements of their capabilities when compared to non-musicians.

It appears not only that musicians have extraordinary motor and sensory skills, and better somatosensory discrimination abilities, but also that, relative 
to non-musicians, they have an increased ability to learn new tasks, and they show enhanced motor and sensory learning capabilities . . . Several studies comparing musicians with non-musicians clearly indicate important structural and functional changes in the brains of the former as a result of intense sensory and motor training associated with musical expertise.

Intense physical training is required to play a musical instrument to a high standard. As Tufano showed, the requirements for the highest achievements in operating a handheld $16 \mathrm{~mm}$ camera are equally exacting. Similar skills are required of many who work within the media industries today: a co-ordination between hand, machine, eye and ear that are not easy to acquire. As Murphy points out, there is a considerable difference between the footage that results from camera movements made by an inexperienced user, and the 'useable move' that will be provided by a skilled user. This is a distinct skill that has to be acquired by practice. Yet we still think of what is learned here as skills or crafts rather than knowledges. There is an implicit downgrading of these 'skills' in relation to other forms of learning. The material engagement approach requires that we re-evaluate our approach to the idea of 'skills' and their acquisition. What we call 'skills' are in fact adaptations of humans to their new circumstances of operation. The change from first acquaintance with a technology to becoming a skilled operator is one of (observable) physical change, and (not yet researched) biological changes as well. Malafouris' material engagement theory offers a means of understanding and theorizing an area that many media studies scholars find mysterious: the area of 'media practice'. More widely, it also enables us to understand the potential of hands on approaches to the study of the relations between technologies and their humans, or humans and their technologies.

In the past, intellectuals have conceived of their own activity of thought as something that can only take place through stratagems of avoidance of the physical: by shrugging off the preoccupations of everyday existence to servants and to women; by regarding the physical world as a necessary encumbrance, to be endured and overcome; by creating ivory towers. The intellectuals of the past, beginning with the early elites who first gained control the surpluses of agriculture, expressed their power through their emancipation from the physical, the better to be able to think and reflect. So the notion that thinking takes place through material engagement runs counter to the long history of intellectual activity and so seems rather more radical or difficult than it is in practice. It runs against a dualism of the physical and the mental which sets the two in opposition to each other. This same dualism is that which Heidegger (1977) identified and criticized in his essay on technology, a dualism that sees thought as existing separate from the physical world and hence able to instrumentalize that world. This attitude he summed up in the idea that humanity to rethink nature as a 'standing reserve', as the raw material that waits for the human intelligence to exploit it. This attitude is that of the Anthropocene: the ability to have, through the application of technologies, a 
profound and pervasive impact on the nature of the world. A hands on approach to knowledge will begin to enable a move away from this mindset, to see the human as the product of a continuing process of material engagement with both nature and technologies. The perception that nature is a 'standing reserve', criticized by Heidegger, is based on the misconception that human intentionality and agency are separate and antecedent to action, rather than produced within the encounter of hybrid agents and the material world.

The self-awareness of the hands on researcher in trying to adopt the adaptations of the skilled operators is important in developing an understanding what those adaptations were. This new methodology, then, requires techniques of physical self-awareness that are different from the contemplative or analytic skills of the past. These new analytic approaches are all the more important as we become aware of the challenges and affordances of our future. We need an awareness both that we are continuously adapting through new material engagements, and that we are actors in a world whose very existence is threatened by our misapprehension of our material engagements as manipulation of a world that stands 'in reserve', ready to do our bidding.

We live in a time when understanding this relationship has become an urgent task. Our period is one in which vast populations are being taken (or are taking themselves) through a whole range of new material engagements, with whole classes of new electronic technologies which are redefining everyday existence. The affordances of these technologies bring with them a large range of new material engagements and hence series of adaptations of our bodies and our minds. We are all digital technicians now, using our opposable thumbs for new purposes, adapting our vision and physical disposition for screen work of different kinds. We are altering our internal perceptions of time as we adapt our management of time. We are substituting writing for speech, moving images for writing. Donna Haraway (1991) famously pointed out that humans have always been cyborgs, moulding and combining their bodies to whatever tool they were using. More recently, Andy Clark has claimed that humans are 'natural-born cyborgs' because of this continuous adaptation of our minds through their material engagements: "Many of our tools are not just external props and aids, but they are deep and integral parts of the problem-solving systems we now identify as human intelligence" (Clark 2004, 5-6). The range of hands on history approaches acknowledges the complex realities of this insight. Hands on approaches will develop an understanding of our place in a world through which thinking becomes possible, together with which we think.

\section{Note}

1 This chapter and the videos to which it refers were produced as part of the ADAPT project funded by the European Research Council (ERC) under the European Union's Horizon 2020 research and innovation programme (grant agreement No. 323626). 


\section{Bibliography}

Bruzzi, Stella (2006) New Documentary: A Critical Introduction. London: Routledge.

Clark, Andy (2004) Natural-Born Cyborgs. Oxford: Oxford University Press.

Ellis, John (2012) Documentary: Witness and Self-Revelation. London: Routledge.

Ellis, J., Murphy, A. and Hall, N., 2018. ADAPT. Available from: https://doi.org/10.17637/ rh.c.3925603.

Ernst, Wolfgang (2012) Digital Memory and the Archive. Minneapolis: University of Minnesota Press.

Frosh, P. and Pinchevski, A. (eds) (2009) Media Witnessing: Testimony in the Age of Mass Communication. London: Palgrave Macmillan.

Geertz, Clifford (1973) The Interpretation of Cultures. New York: Basic Books.

Grigor, Murray (1991) Distilling Whisky Galore. London: Large Door/Channel 4 Television, 8 January.

Haraway, Donna (1991) A Cyborg Manifesto: Science, Technology, and Socialist-Feminism in the Late Twentieth Century. In Simians, Cyborgs and Women: The Reinvention of Nature. London: Routledge.

Heidegger, Martin (1977) The Question Concerning Technology. New York: Taylor \& Francis.

Huhtamo, Erkki and Parikka, Jussi (eds) (2011) Media Archaeologies: Approaches, Applications, and Implications. Berkeley, CA: University of California Press.

Latour, Bruno (1999) Pandora's Hope: Essays on the Reality of Science Studies. Cambridge, MA: Harvard University Press.

Malafouris, Lambros (2013) How Things Shape the Mind: A Theory of Material Engagement. Boston, MA: MIT Press.

Miller, Daniel (2010) Stuff. Cambridge: Polity Press.

Nichols, Bill (1991) Representing Reality: Issues and Concepts in Documentary. Bloomington: Indiana University Press.

Parikka, Jussi (2012) What is Media Archaeology? Cambridge: Polity Press.

Renov, Michael (1993) Theorizing Documentary. New York: Routledge.

Stiegler, Bernard (1998) Technics and Time 1. Stanford, CA: Stanford University Press. 